\title{
RUBRICA E FEEDBACK NO PROCESSO DE AVALIAÇÃO: O ESTUDANTE COMPREENDE?
}

\author{
SÃO PAULO/SP MAIO/2018 \\ Marcela Inafuku - Laureate - marcela.inafuku@eadlaureate.com.br
Fabiana Bana - Laureate - fabiana.bana@fmu.br \\ Tipo: Relato de Experiência Inovadora (EI) \\ Categoria: Pesquisa e Avaliação \\ Setor Educacional: EDUCAÇÃO SUPERIOR
}

\begin{abstract}
RESUMO
O Ensino a Distância vem em uma crescente, na medida em que facilita o acesso de ensino com qualidade. Em disciplinas online, o estudante desenvolve diversas características, entre elas, sua proatividade e autonomia. Para ter a melhor experiência deste ensino-aprendizado, se faz importante instrumentos e ferramentas que auxiliem tanto o estudante como o docente.

A proposta deste estudo é analisar a rubrica e o feedback como ferramentas de avaliação da aprendizagem, na modalidade $20 \%$ de disciplinas online dos cursos presenciais, por meio de um questionário disponibilizado aos estudantes de diversos cursos. Pela análise dos resultados, é possível verificar a importância da compreensão do estudante destas ferramentas.
\end{abstract}

Palavras-chave: rubricas, feedback, atividades dissertativas 


\section{INTRODUÇÃO}

No ensino a distância, o docente é peça fundamental no processo de aprendizagem do estudante. O desafio é complexo, uma vez que é de sua responsabilidade fazer com que cada estudante interaja com as atividades e com os demais colegas, sentindo-se acolhido, como se fosse em suas disciplinas presenciais.

Existe também a dificuldade na utilização das tecnologias de informação, não somente por parte dos estudantes, mas também pelo próprio docente, que ainda tem o papel de conscientizar o aluno sobre a construção do seu conhecimento dentro deste ambiente virtual de aprendizagem.

Em uma disciplina presencial, para o docente verificar se conseguiu atingir o máximo no processo de ensino-aprendizagem, pode utilizar de diversos recursos, como seminário, prova oral, elaboração de trabalhos individuais ou em grupos, etc.

Já em disciplinas online, um importante instrumento é a avaliação por meio das atividades, que possibilita o controle periódico do processo acadêmico dos alunos, propiciando uma avaliação contínua (Mercado, 2008).

Ainda, segundo o autor, na educação online, a avaliação formativa pode ser realizada por meio do acompanhamento das participações dos alunos nas atividades propostas pelo curso, tendo como fonte os registros deixados nas diferentes ferramentas disponibilizadas no ambiente virtual do curso.

Assim, o aumento da demanda em disciplinas online também faz com que os docentes necessitem utilizar ferramentas que agilizem o processo e o prazo de correções, ao mesmo tempo em que, forneçam ao estudante uma experiência de aprendizado eficaz $e$ consistente.

Para Felício (2013), ao utilizarmos os instrumentos para avaliar o aluno, o professor deve deixar claro o objetivo, sempre utilizando linguagem clara e evitando ambiguidades. Sem objetivos e linguagem clara o aluno pode ser levado a responder exatamente o que está sendo pedido. Nesse caso, o professor deve ser evitar, pois compromete o significado da frase.

\section{RUBRICA E FEEDBACK}

Uma das ferramentas eficazes na avaliação dos estudantes no ambiente virtual de 
aprendizagem são as rubricas.

Felicio (2013) define o termo Rubrics (Rubricas) tendo origem na palavra inglesa "Rules" (regras) e são estas regras estabelecidas desde o início do processo que orientam os alunos por quais caminhos podem/devem trilhar para potencializar sua aprendizagem.

Assim, a rubrica é uma ferramenta que define os critérios de avaliação e que auxilia no entendimento do estudante de como será avaliado, a fim de verificar o nível de suas competências, bem como se atingiram as expectativas do docente.

A rubrica deve focar o objetivo a ser atingido, sendo classificado em níveis de desempenho como forma de classificação.

É importante também que, mais do que atingir o objetivo de determinada atividade, o estudante também seja motivado, levando-o a refletir sobre suas respostas de acordo com o tema abordado na atividade.

Mercado (2008) afirma que a função da avaliação dispensada ao aluno é dar a ele o apoio e o feedback necessários à ampliação de sua aprendizagem.

HATTGE (2014) define bem sobre o termo feedback:

[...] é muito utilizado na Educação a Distância, sendo um retorno, um parecer, uma devolutiva a respeito da atividade realizada pelo aluno com objetivo de acompanhar o seu desempenho. É uma maneira de professor estar avaliando o aluno considerando os pontos positivos e os pontos a melhorar na atividade proposta, tendo em vista a melhoria do mesmo e ao mesmo tempo aproximar o aluno do professor e demais alunos e consequentemente do curso fazendo com que se sintam verdadeiramente numa sala de aula, mesmo estando geograficamente separados.

Um feedback eficaz e constante, principalmente em um ambiente virtual de aprendizagem, é de suma importância para motivação do estudante nas disciplinas, mas não somente no sentido de parabenizar por atingir o objetivo de determinada atividade, mas também em apontar quais são os pontos que devem ser melhorados, levando-o a uma reflexão autocrítica. Além disso, auxilia também o docente a verificar as dificuldades e avanços do seu próprio método de avaliação, sendo este um meio e não o fim do processo de aprendizagem.

O objetivo deste estudo é verificar se os estudantes compreendem a importância da 
rubrica e do feedback no processo de ensino-aprendizagem.

\section{ANÁLISE DOS DADOS E RESULTADOS}

A pesquisa foi realizada com estudantes dos cursos presenciais, do primeiro semestre de 2018 , que realizam $20 \%$ de disciplinas online no ambiente virtual de aprendizagem Blackboard. Todas as disciplinas estão relacionadas com o tema da área de Direito, mas para cursos diversificados, como Arquitetura e Urbanismo, Ciências Contábeis, Administração, Marketing, Gestão de Recursos Humanos, etc.

Neste estudo, o objetivo geral foi analisar, mediante os critérios de avaliação, o efeito da rubrica e do feedback nas atividades avaliativas dissertativas.

No ambiente virtual de aprendizagem, cada disciplina possui quatro unidades com diversos recursos cada: game, quiz, e-books, vídeos, quadro de avisos e recursos de mensagens.

Todas as atividades avaliativas do ambiente virtual de aprendizagem são compostas por questões objetivas e dissertativas. A análise foi realizada nas questões dissertativas compostas pelas Unidades 1 e 3 . A Unidade 1 é composta por um fórum de participação, no qual o estudante deve realizar sua participação, respondendo a questão, e ainda comentar sobre as respostas dadas por seus colegas, podendo participar livremente até determinada data de encerramento da atividade. Já a atividade 3 é composta por uma única questão dissertativa, na qual o estudante tem apenas uma chance de participação.

Embora sejam atividades distintas, as rubricas e os feedbacks foram utilizados em ambas. No caso do feedback, este ficava disponível após o estudante responder a questão, variando entre o nível proficiente, utilizando a frase "Parabéns, você se atentou ao tema proposto" e como nível não satisfatório foi utilizada a frase "Cuidado, você não se atentou ao que foi solicitado no enunciado". Entre estes níveis ainda foram utilizados os termos competente, satisfatório e aprendiz, indicando quais deveriam ser os pontos de melhoria do estudante.

Quanto ao questionário, este foi aplicado entre os dias 23/04/2018 a 02/05/2018, desenvolvido por meio de formulário online, no qual os gráficos são gerados automaticamente. Foi postado um link no quadro de avisos de cada disciplina, com os seguintes resultados: 
Entre as 552 respostas, 68,3\% (377) foram realizadas por estudantes do sexo feminino (Figura 1).

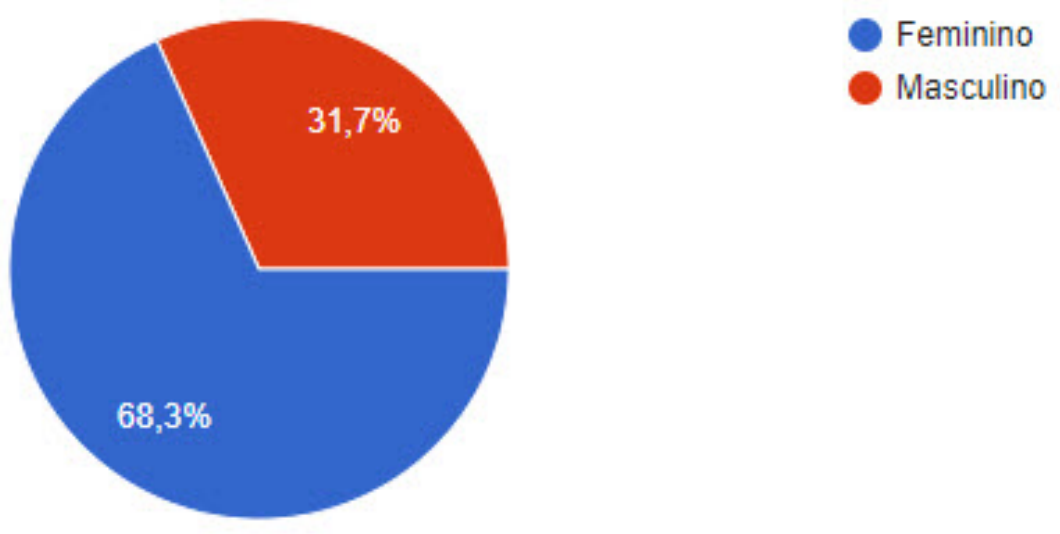

(Figura 1)

Já quanto a faixa etária, predominou-se entre 21 a 28 anos $(47,6 \%)$, seguido pela faixa etária de 29 a 39 anos (25\%) e de 4050 aos (13\%). Já a quantidade de estudantes acima de 51 anos é baixa, contando com 2,5\%, ou sejam, apenas 14 dos 552 estudantes (Figura 2).

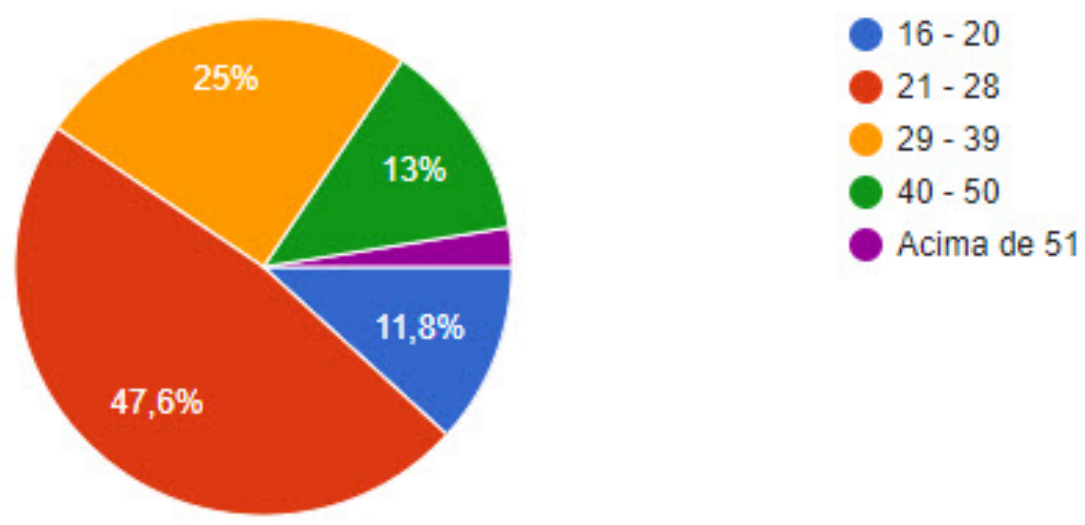

(Figura 2)

Quando questionados sobre o tempo entre a conclusão do Ensino Médio e o ingresso na Universidade, é expressivo o número de estudantes que ingressaram imediatamente ou em até 2 anos após a conclusão do Ensino Médio, perfazendo o total de 50,9\%. Em 
grande número também estão os estudantes que ingressaram na Universidade após mais de 6 anos da conclusão do Ensino Médio (Figura 3).

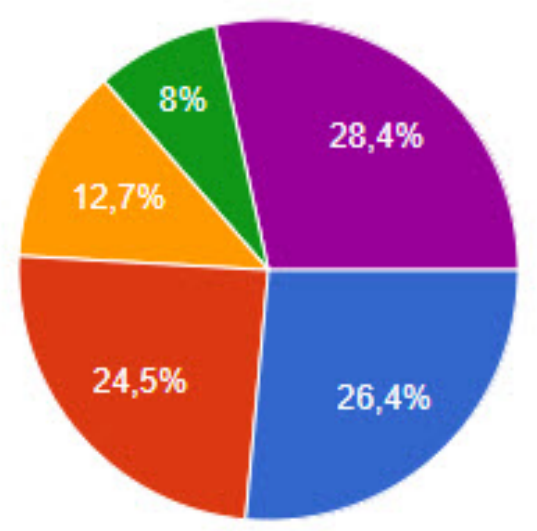

Imediatamente.

Entre 1 e 2 anos.

Entre 3 e 4 anos.

Entre 5 e 6 anos.

Mais de 6 anos.

(Figura 3)

Nas duas atividades dissertativas, além da exposição da questão, os estudantes deveriam acessar os critérios de avaliação por meio de um link. Todos os critérios expostos estavam de acordo com as rubricas, sendo que, também estavam discriminadas a porcentagem de pontuação, de acordo com o cumprimento do critério. Do total, $79 \%$ dos estudantes responderam que os critérios estavam descritos de forma clara (Figura 4).

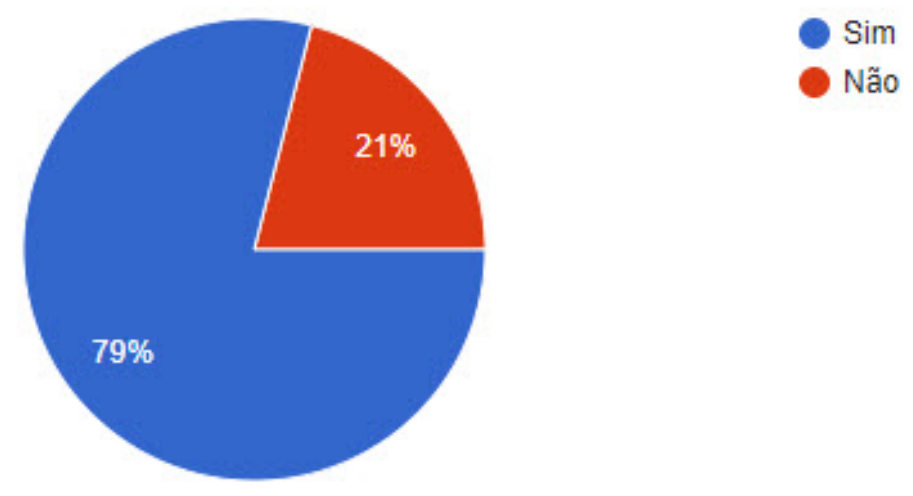

(Figura 4)

Quando questionados se sabiam o que é rubrica, 89,7\% afirmaram que sim, conheciam a rubrica. Já $10,3 \%$ (57) dos estudantes afirmaram que não sabem o que é rubrica. 
Os estudantes foram questionados se visualizaram o feedback dado pela professora nas atividades. Da totalidade das respostas, 217 estudantes não visualizaram o feedback (Figura 5). Acredita-se que este mesmo número de estudantes não tenham visualizado as rubricas, uma vez que, os feedbacks das atividades ficavam disponíveis dentro da própria rubrica, após a correção da docente. O estudante poderia consultar o seu feedback dentro de um link do ambiente virtual de aprendizagem, denominado "Minhas Notas".

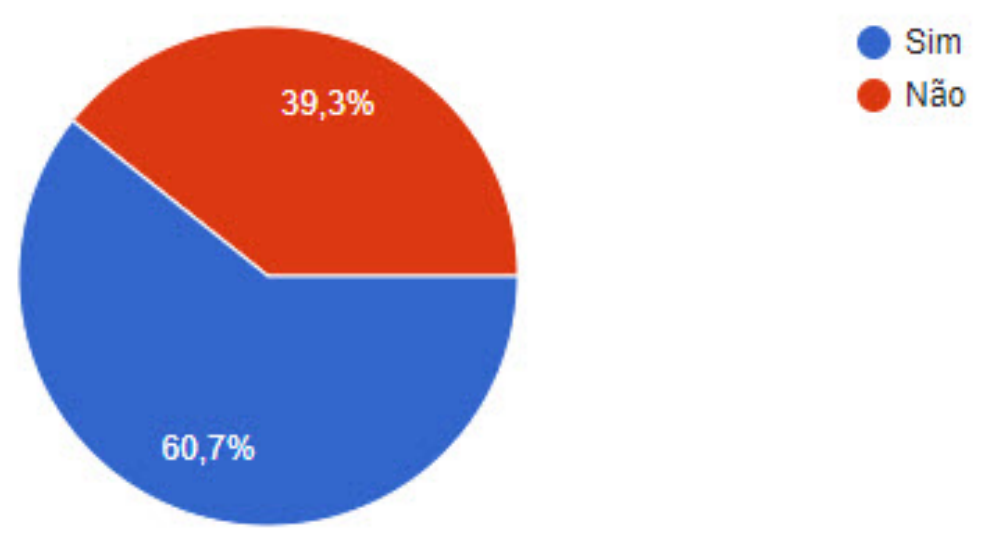

(Figura 5)

Ao serem questionados sobre a concordância sobre o feedback, 49,3\% concordaram. Já o número de estudantes que não se atentaram ao feedback também foi grande, 39,5\% (218 das 552 respostas) e 11,2\% não concordaram com o feedback obtido.

Ao serem questionados se os estudantes entenderam a pontuação recebida após ler o feedback dado pela docente, 50\% entenderam (Figura 6). Já 11,6\% não entenderam. Já os que informaram que não visualizaram o feedback cai para $38,4 \%$ (212 das 552). 


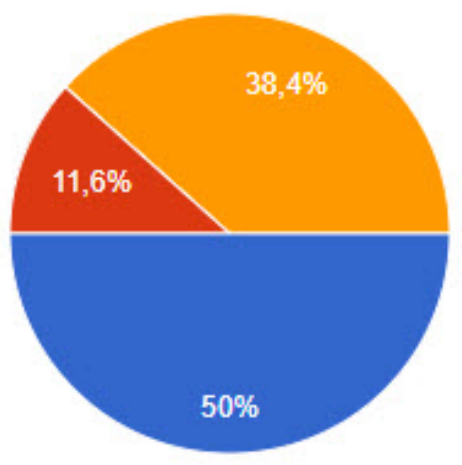

(Figura 6)

Quando questionados se, o feedback auxiliou na compreensão da questão, 46,6\% afirmaram que sim. Já 15\% informaram que o feedback não auxiliou na compreensão da questão e mantiveram-se os $38,4 \%$ informando que não visualizaram o feedback (Figura 7).

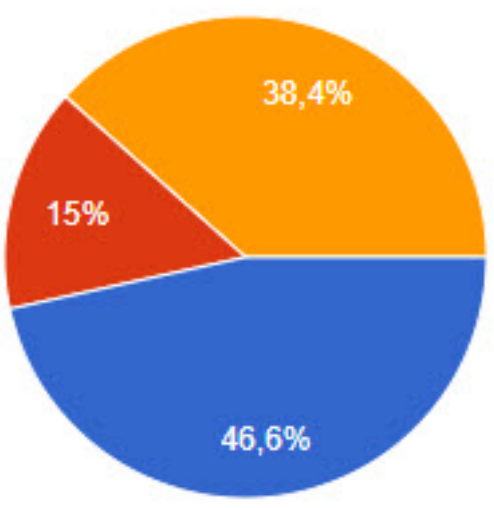

(Figura 7)

\section{CONCLUSÃO}

Pela análise dos dados é possível verificar que, grande parte dos estudantes estão na faixa etária adulta (entre 21 e 28 anos), assim como encontra-se equilibrado o tempo entre o término do Ensino Médio e o ingresso na Universidade entre aqueles que ingressaram até dois anos após o termino e aqueles que ingressaram na Universidade 
após 6 anos ou mais.

Embora um número expressivo de estudantes saibam o que é rubrica, também houve um número expressivo de estudantes que não visualizaram o feedback de suas atividades avaliativas.

É possível verificar que o feedback auxiliou na compreensão da questão para grande maioria dos estudantes, podendo haver um número maior, se todos tivessem visualizado o feedback (212 não visualizaram).

A utilização da rubrica se faz importante para estabelecer uma forma de avaliação equilibrada, uma vez que, a utilização para correção tem seus critérios definidos.

Outro fator importante da rubrica é no que diz respeito ao tempo do docente para correções das atividades dissertativas, sendo que, ao contrário das atividades objetivas, na qual a correção é realizada automaticamente pelo ambiente virtual, na atividade dissertativa se faz necessária a leitura pelo docente. Inserindo o feedback dentro das próprias rubricas, além de diminuir o tempo de lançamento de nota da atividade, também auxilia a motivação do estudante, uma vez que, ainda é comum os docentes apenas lançarem a nota, sem um retorno sobre a resposta do estudante, tendo em vista o curto período e a grande quantidade de atividades para correção.

Se faz importante estabelecer rubricas precisas, com feedbacks adequados a proposta avaliativa, orientando os estudantes a atingir os objetivos da disciplina, bem como medindo e incentivando o conhecimento e aprendizagem, auxiliando no pensamento crítico e contínuo.

A partir da pesquisa aplicada, observa-se a fragilidade do estudante na visualização das rubricas e dos feedbacks, verificando ainda que, a idade ou o tempo longe dos estudos não são fatores determinantes desta fragilidade. É necessária uma pesquisa mais aprofundada, com o desenvolvimento de métodos que auxiliem e incentivem tanto os estudantes como os docentes a tornar um hábito a aferição destas ferramentas, tão importantes nas avaliações online e para a autonomia de aprendizagem destes estudantes.

\section{REFERÊNCIAS BIBLIOGRÁFICAS}

FELICIO, Aline Cazarini; CARITÁ, Edilson Carlos; NETO, Jose Dutra de Oliveira. Percepção discente quanto à utilização de rubricas para avaliação da aprendizagem. 
Disponível em . Acesso em 20/04/2018.

MERCADO, Luís Paulo Leopoldo. Ferramentas de Avaliação na Educação Online. In: IX CONGRESSO IBEROAMERICANO DE INFORMÁTICA EDUCATIVA. 2008. p. 1-14.

HATTGE, Andrea Adriani Gosenheimer; RIBAS, Cíntia Cargnin Cavalheiro; PAULO, Andrea Barbosa Delfini. A importância do feedback do tutor on-line no ensino a distância. ENSAIOS PEDAGÓGICOS Revista Eletrônica do Curso de Pedagogia das Faculdades-OPET, 2014. 